\title{
THE AMERICAN JOURNAL OF PATHOLOGY $+=$
}

\begin{tabular}{lll}
\hline \hline VoltMe XV & JULY, I939 & NUMBer 4 \\
\hline \hline
\end{tabular}

\section{CYTOLOGICAL CHANGES INDUCED IN THE HYPOPHYSIS BY THE PROLONGED ADMINISTRATION OF PITUITARY EXTRACT *}

A. E. Severinghats, M.D., and K. W. Thompson, M.D.

(From the Department of Anatomy, College of Physicians and Surgeons, Columbia University, New York City, and from the Laboratories of Surgery and Physiological Chemistry of the School of Medicine, Yale University, New Haven, Conn.)

When Harvey Cushing first described the syndrome that now bears his name he promptly appreciated the fact that pituitary basophilism, as was true of acromegaly (i.e. pituitary acidophilism), would be better understood if it could be experimentally reproduced. An attempt to achieve this result by the injection into a puppy of a crude pituitary gonadotropic extract (presumably of basophilic elements) was described in 1934 by Thompson and Cushing. ${ }^{30}$ While the animal developed a condition bearing certain resemblances to the clinical syndrome, it showed at the same time effects more or less characteristic of pituitary deficiency, namely, inactivation of the thyroid, adrenal cortex and gonads, and a failure to grow.

Equally striking results obtained in attempts to reproduce the syndrome in other animals subsequently led one of us (K.W.T.) to make a correlated study of the antihormones, discovered by Collip and his co-workers, ${ }^{1,3,4}$ in order to interpret the rôles these substances may have played in the injected animals. These

* Aided by grants of funds from the Josiah Macy Jr. Foundation, from the Therapeutic Research Committee of the Council on Pharmacy and Chemistry, and from the Rockefeller Foundation.

Received for publication April 4, 1939. 
studies established the non-species-specific quality of the antihormones, ${ }^{15,27,31}$ and accounted for the observed inactivation of the animals' own pituitary hormones.

The evidence now available from several sources (Du Shane et al. ${ }^{6}$ Gordon et al.,${ }^{7}$ Rowlands and Parkes, ${ }^{15,}{ }^{16}$ and Twombly ${ }^{32}$ ) suggests that the antihormones are antibodies which are formed in the injected animal in response to an antigen to which is linked the pituitary hormone. The antihormones are readily produced when crude pituitary extracts from a foreign species are injected into an animal, but not when these extracts are sufficiently purified or the antigenic complex is separated from the hormone (Werner, ${ }^{35,36,37}$ confirmed by Thompson, unpublished experiments). These antisubstances have not usually developed when the test animal has been injected with extracts derived from the same species (sheep pituitaries in sheep, Rowlands, ${ }^{14}$ Thompson, ${ }^{26}$ Collip ${ }^{3 *}$; rat pituitaries in rats, Smith ${ }^{24,25}$; and prolan in man, Twombly ${ }^{32}$ ). When first developed in the animal, the antihormone is ordinarily specific only for the extract injected, but after prolonged injections under suitable conditions the antihormones become non-species-specific; in other words, they inactivate the like hormones from many species of animals including those of the injected animal itself (unpublished data, Thompson).

Definite physiological effects are caused by the antihormones in animals. The gonadotropic antihormone, for example, under suitable conditions causes: ( $\mathrm{I}$ ) an inactivation in test rats of gonadotropic hormones from several species of animals, including $\operatorname{man}{ }^{15,30}$; (2) the failure of the sexual maturity of young rats ${ }^{30}$; and (3) the abortion of mice, ${ }^{30}$ rats, ${ }^{30}$ rabbits ${ }^{11,30}$ and dogs ${ }^{29}$ (the latter 2 species may thus be aborted at any stage of pregnancy). Anderson and Collip have reported the lowering of the basal metabolic rate of animals treated with thyrotropic antihormone. ${ }^{1,4}$

While these antihormone studies were in progress, clinical case reports of the so-called Cushing syndrome from various sources made it clear that a condition almost indistinguishable from that accompanying a basophilic adenoma may occur with an adenoma or carcinoma of the adrenal cortex, ${ }^{2,8}$ an oat-cell tumor or carci-

\footnotetext{
* Collip observed weak antihormones in the serum of 2 out of 4 sheep that had been injected with sheep extract. It is conceivable that denaturation of the extract may have been responsible for the results.
} 
noma of the thymus, ${ }^{9}$ and in a few instances with no demonstrable adenoma of any organ (unreported cases). Furthermore, Crooke ${ }^{5}$ and later Rasmussen ${ }^{12}$ noted a characteristic cytoplasmic hyalinization in the basophilic cells of the pituitary in verified cases with the syndrome. This change is found in most of the basophilic cells of the anterior lobe, but it does not occur in the cells of the basophilic adenoma itself, should one be present. These specific changes have been observed only in the glands removed from human cases and heretofore have not been described in experimental animals. Crooke claimed this basophilic hyalinization to be the only single "pathological common denominator," possibly the essential lesion, of the syndrome.

An analysis of the data concerned with the Cushing syndrome made it appear more than likely that in the antihormone experiments some associated changes in the anterior pituitary glands of the animals might also be expected, and certainly should be sought.

The present report concerns itself with a study of the cytological changes in the pituitary glands of three groups of animals (A, $B$ and C), some of which had been subjects for the attempts to reproduce the clinical syndrome of basophilism, and others of which were subjects for the investigation of the antihormones.

The pituitaries first studied were those from 2 dogs (A) that had received prolonged injections of a crude sheep pituitary extract. Marked cytological changes appeared in these glands. It was impossible to say whether the changes in these two hypophyses were due directly to the injected extract or to the physiological action of the antihormones which were extremely active in the serums of these animals. There are, to the authors' knowledge, no cytological data to indicate what effect, if any, the antihormones have upon the anterior pituitary gland. To this end 2 other dogs (B) were injected with a suitable antihormone serum, in order that their hypophyses might be studied. The third pair of glands to be studied were the hypophyses of 2 sheep (C) which did not develop antihormones during a prolonged course of injections of the sheep extract. Before proceeding to a cytological description of the hypophyses of these animals, it seems advisable to state briefly the experimental observations. 


\section{The Antmals}

\section{(A) The Dogs Injected with Sheep Pituitary Extract}

Dog No. I: A female fox terrier puppy was injected daily for 4 months with $25 \mathrm{cc}$. of an extract of sheep pituitary glands. This extract, which had been used in many of the antihormone experiments of one of the authors (K. W. T.), was prepared by alcohol precipitation after a method described by van Dyke and WallenLawrence. $^{33}$ A marked atrophy of the thyroid, adrenals and gonads was noted and reported in the aforementioned publication (Thompson and Cushing ${ }^{30}$ ). The grossly normal pituitary gland was preserved for future study. The antihormones were not investigated in this animal, but later observations of other puppies similarly treated have indicated that the effects observed may be attributed largely to these very active antisubstances.

Dog No. 2: An adult female shepherd dog was injected daily for 210 days with $25 \mathrm{cc}$. of an extract identical with that given to dog No. I. The animal at first developed in her serum the augmentary principle (Thompson ${ }^{28}$ ), and she later developed, in succession, antihormones for the gonadotropic hormone of sheep pituitary extract, pregnant mare serum, and human pituitary glands. During the period of the injections this animal's fur became coarse and sparse, as if she had been thyroidectomized, and she developed hypercholesterolemia. At autopsy the thyroid, adrenals and gonads were found to be atrophied. The thyroid epithelium, fixed in Zenker's plus acetic acid, was flattened, and the colloid had no absorption vacuoles.

\section{(B) The Dogs Injected with Canine Antihormone}

Dog No. 3: An adult female mongrel dog was injected subcutaneously daily for a period of 32 days with ro cc. of canine antihormone serum. The donor was a Collie dog that had been injected daily for 3 years with the above mentioned sheep pituitary extract. This particular serum inactivated the gonadotropic hormones of many species, and it invariably produced abortion of pregnant dogs. In addition to the antihormones the serum contained considerable amounts of the antidiuretic principle, which 
also was present in the sheep extract. The serum did not contain a measurable amount of the oxytocic principle.*

At autopsy the pituitary gland of the dog injected with this serum was grossly normal, but the thyroid, adrenals and gonads appeared smaller than normal. Histologically the thyroid showed all the signs of subnormal functional activity. This animal did not develop hypercholesterolemia.

Dog No. 4: An adult female mongrel dog was injected daily for 30 days with Io cc. of the same antiserum. The serum in this case was injected intramuscularly on one day and intravenously the next day because the intravenous route of administration was found to be more satisfactory for the induction of abortion of pregnant dogs. At autopsy the thyroid, adrenals and gonads appeared inactive. Histologically the thyroid was slightly more active than that of dog No. 3, but it was no more active than normal. This animal also failed to show hypercholesterolemia.

\section{(C) The Sheep Injected with Sheep Pituitary Extract}

Ewe No. I: An immature ewe was injected daily, beginning at the age of 4 months, with $25 \mathrm{cc}$. of the same sheep pituitary extract that was given to dogs Nos. I and 2. During the subsequent 6 months this ewe's serum was tested at intervals and was found to contain no gonadotropic antihormone. Before the injections were started, however, the serum contained a principle which inactivated thyrotropic hormone. During the period of injections the genitalia and nipples continually showed signs of stimulation, and at autopsy, after 6 months of injections, the internal genitalia were found to be considerably hypertrophied. As compared to a half-sister control of the same age, the adrenals and thyroid were approximately normal. Histologically the thyroid showed a normal degree of activity. The hypophysis was normal in size.

Ewe No. 2: This ewe, a twin of ewe No. I, was subjected to similar treatment except that the extract injected was prepared by alkaline extraction of an acetone-dried powder of sheep pituitary glands. This animal did not develop gonadotropic antihor-

\footnotetext{
* For the tests of the posterior lobe principles, the authors are indebted to Dr. Alfred Z. Gilman of the Laboratory of Pharmacology, Yale University Medical School, New Haven, Conn.
} 
mones, and the autopsy revealed the same effects of the injections as were found in ewe No. $I$.

Ewe No. 3: The control lamb was a half-sister of ewes Nos. I and 2. Their parents were from a highly inbred stock. The control was fed approximately the same diet and was ro months old when autopsied. Her serum contained no gonadotropic antihormone, but, like the other 2 lambs, contained an antithyrotropic principle. Her gonads and uterus were not hypertrophied.

\section{The Cytology of the Pituitary Gland}

Technical Methods: The pituitary gland of dog No. I was removed 2 hours after death and fixed in neutral ro per cent formalin. All other hypophyses were removed promptly after the death of the animal by air embolism and immediately fixed in Zenker-formalin.

A brief outline of the technic used to prepare the tissues for microscopic examination is given below:

I. After 8-24 hours fixation, tissues are washed in running water for 15 hours and then run through graded alcohols to 95 per cent alcohol where they remain for 5-12 hours, depending on the size of the tissue block. The tissue is then placed in absolute alcohol to which is added an equal volume of ether. After 2 hours, an equal volume of 2 per cent celloidin is added. The tissue then remains in this mixture for 5-18 hours.

2. Tissue is run through celloidin as follows: 48 hours in 2 per cent, 48 hours in 4 per cent, and 48 hours in 6 per cent. The tissue is then cast in 6 per cent celloidin in paper boxes and is hardened overnight in chloroform vapor in an air-tight jar. Next, trim the celloidin as close to the tissue as possible and place the block in carbon disulphide for $\mathbf{2 4}$ hours or longer if the block continues to float.

3. Place the block in carbon disulphide-paraffin mash (equal parts $62^{\circ}$ C. paraffin and carbon disulphide) for 5-7 days in a place just sufficiently warm to keep the paraffin melted. Carry the block through I change of melted $62^{\circ} \mathrm{C}$. paraffin for from 5-25 minutes and cast in freshly filtered $62^{\circ} \mathrm{C}$. paraffin which has been heated to about $70^{\circ} \mathrm{C}$. Immerse in warm water (not over $45^{\circ} \mathrm{C}$.) for hardening.

4. If the tissues are brittle or difficult to cut, shave the block 
until a small portion of the tissue is exposed and submerge in water for from 2 to 5 days before sectioning. Ice, or ice water, is usually necessary to keep the knife and the block cold during cutting at 2 or $3 \mu$.

5. The following mixture is used for mounting and spreading the sections (after egg albumin has been applied to the slide). To ro cc. of acetone add 5 drops of methylbenzoate and mix well; add $40 \mathrm{cc}$. of distilled water. In spreading the sections, the best results are obtained by rapid cautious use of a hot plate at a temperature 5-10 degrees higher than the melting point of the paraffin used.

Staining: Sections are run through xylol and absolute alcohol into a solution of 3 parts of oil of cloves and I part of absolute alcohol for to minutes. Proceed through graded alcohols to distilled water. Flood the slides with Altmann's 20 per cent acid fuchsin solution and gently heat to steaming (with an alcohol lamp). Allow 5 minutes for cooling. Differentiate, if necessary, in picric acid alcohol as recommended in the Altmann method ( 1 part of saturated alcoholic picric acid and 7 parts of 20 per cent alcohol).

Wash the slides carefully in distilled water and place in I per cent phosphomolybdic acid for from I to 2 hours. Place the slides directly (do not rinse) into aniline blue as prepared by Masson for about I hour (longer or shorter time as required). Wash the slides in distilled water and shake off the excess water. Rinse quickly in 95 per cent alcohol and absolute alcohol, clear in xylol and mount.

If desired, hematoxylin may be successfully used as a nuclear stain. It should precede the acid fuchsin.

\section{(A) Anterior Bypophyses of Dogs Injected for an Extended Period with Sheep Pituitary Extract}

The hypophyses of dogs Nos. I and 2 are profoundly altered. Although essentially similar, the cytological changes are more pronounced in dog No. 2 and may be attributed to the much longer period of injection. The basophils are much larger than normal. In some the distinct cytoplasmic granulation, characteristic of the basophils in dogs, is still present. In many cells, however, the character of the granulation has changed. Granules are frequently 
gathered into spherical masses of irregular size, as shown in Figures $1-6$. While such cells may be found by search in the normal hypophyses, there is no question of their great numerical increase in these injected dogs.

Most of the basophils show extensive vacuolation. The vacuoles are of three types. In the first type they appear as clear spaces, suggesting that they contain a non-stainable substance, or that the original substance has been technically removed (Figs. I924). A second group of vacuoles is filled with a substance staining a clear pale blue. These vacuoles in early stages are small and scattered throughout the cytoplasm. In other cells the vacuoles have coalesced to form more extensive vacuolar inclusions. A third type, perhaps the most common, has a deeply basophilic amorphous substance. Here again, many cells will show small vacuoles distributed among the coarse masses of basophilic granules (Figs. 7-1 7). In later stages the vacuoles have expanded and united to occupy large portions of the cell, or have replaced the granular cytoplasm almost entirely. Figures $I$ I and 12 show that the large vacuoles are formed by coalescence of the smaller ones.

In this widespread disturbance of the basophils it is readily possible to demonstrate cells in which the vacuolation is identical with that in the typical castration cell of the rat or monkey (Fig. 17). Other basophils contain the more extensive irregular vacuolar distortion regularly seen in the hypophysis of the thyroidectomized rat (Fig. 22). Still other cells show a combination of granular and liquefied areas which are indistinguishable from the hyalinization of basophils described by Crooke in the Cushing syndrome of pituitary basophilism (Fig. 3I).

The fact is evident that regardless of their final configurations, the types of vacuolation begin in a similar manner, essentially a liquefaction of the cytoplasmic granules to give a basophilic amorphous substance, perhaps better called colloid-like than hyaline. Previous careful cytological analysis of the onset of basophilic changes which follow castration and thyroidectomy have shown that the early stages of vacuolation are indistinguishable. Experimental evidence supports the contention that these vacuolations are inseparable for it is possible to prevent or remove vacuolation after thyroidectomy by administration of estrone in doses still within the physiological range $(2-5$ r. u. per day) 
(Severinghaus, ${ }^{22}$ and Nelson and Hickman ${ }^{10}$ ). Castration changes, conversely, have not been cleared up by the administration of thyroxin. One might expect that this would be difficult to accomplish, for strangely enough basophilic vacuolation occurs in both hypo- and hyperthyroid conditions (Severinghaus et al. ${ }^{18,19}$ ).

The study of the hypophyses of these massively injected dogs points still more clearly to the conclusion that basophilic vacuolation is a characteristic retrogressive alteration which the cells undergo when their normal physiology is disturbed. A previous suggestion that the Cushing syndrome is one of these disturbances now seems even more justified, and we are inclined to regard the Crooke changes as an aspect of the general granule liquefaction which also appears after castration or thyroidectomy.

Furthermore, a study of these glands again confirms one in the opinion that all of these basophilic changes are atrophic in character. This in no sense implies that the destruction of cytoplasmic granulation through liquefaction produces a substance which is hormonally impotent. There is, however, no good experimental evidence to indicate that the widespread vacuolation due to either castration or thyroidectomy is associated with any increase in the respective gonadotropic or thyrotropic hormone content of the anterior hypophysis. The increase of gonadotropic hormone which occurs after castration is much more logically related to the great increase of large granular basophils, while after thyroidectomy, if any increase in the thyrotropic hormone content occurs, which is very questionable, the same correlation is indicated.

Sizeable areas in the hypophyses of these dogs are composed of secretory active basophils. These cells cannot be identified by reference to the Golgi apparatus, for the Golgi region differences between the two types of chromophils in the dog's hypophysis are not clear-cut.. ${ }^{17}$ The cells, however, have the general characteristics of basophils. They are much larger than acidophils (Fig. 25). The cytoplasmic granulation is fine and stains a light slate blue color rather than the dark blue of the typical basophil. The mitochondria, though faultily preserved with Zenker-formalin, are numerous and the Golgi region is hypertrophied. These cytoplasmic features indicate a metabolically active cell, producing and liberating a secretory product at a rate above normal. The cells seem to have developed from the chromophobes which are 
now entirely missing from such regions. It is not impossible that these basophils which are now in a phase of hyperactivity will later succumb to atrophic vacuolar changes.

There is some clinical evidence to indicate that patients with the Cushing syndrome pass through a period of hyperthyroidism which is followed by hypothyroid symptoms. This reversal of thyroid activity would produce correlated anterior lobe changes.

The changes which the acidophils of the injected dogs undergo are much less spectacular, but nevertheless real. If the proportion of acidophilic cells differs from the normal, it could be established only by statistical methods on a much larger series of animals. Suffice it to say that acidophils are abundant. From the fact that basophilic changes in these glands resemble in part those which follow thyroidectomy, the reader may have expected a great diminution or even an absence of acidophils. However, thyroidectomy in the dog does not result in the striking disappearance of acidophils which one sees, for example, in the anterior hypophysis of the rat (unpublished data, Severinghaus).

Acidophilic regions of the gland do not present a uniform appearance. In certain areas the cells are small and irregularly shrunken, with varying degrees of granulation. They have pyknotic nuclei which stain deeply basophilic (Fig. 27). Scattered among these acidophils are many chromophobic cells with exactly the same nuclear characteristics. These two types of cells are typical of stages in the reversion of acidophils to chromophobes in the cycle of secretion previously described in the human hypophysis. ${ }^{21,23}$ Such acidophils will revert to chromophobes but after a nuclear reorganization may at any time begin a new cycle of acidophilic activity. In this connection it is interesting to record that large areas of normal acidophils and chromophobes are also characteristic of the anterior lobe of these injected dogs (Fig. 26).

Finally, it may be pointed out that whereas the dog's anterior pituitary gland contains many small basophilic colloid bodies, they seem decidedly increased in these experimental animals. These masses are frequently surrounded by a row of cells so that they occupy the center of a cord of cells. At other times they appear along the connective tissue framework of the gland and are therefore between the cell cords. Ciliated cells have been seen on occasions to border upon larger colloid inclusions, but these 
seem different in character from those described above. The origin and nature of the colloid remains obscure.

\section{(B) Anterior Hypophyses of Dogs Injected with Canine}

\section{Antihormone}

A single glance at the anterior hypophyses of these dogs reveals that they have undergone striking alterations. Four features are especially striking: (I) the scarcity of typical areas of chromophobic cells; (2) the replacement of normal basophils by hyalinized or vacuolated cells, or by large sparsely granulated cells rich in mitochondria; (3) modifications in the acidophils; and (4) a marked hyperemia and edema of the gland.

The absence of the usual large number of chromophobes gives the anterior lobe a highly granular appearance. Chromophobes have not entirely disappeared, but they are greatly reduced and scattered individually throughout the glandular stroma, in contrast with the grouped arrangement of the normal gland. This unquestionably adds to the impression of their scarcity (Fig. 32).

The decrease in chromophobes is directly correlated with a marked numerical increase of large granulated cells of basophilic character. The coloration of these cells is extremely variable. It varies from the occasional normal dark blue of the normal basophil through varying shades of purple with an increasing reddish cast. Granulation is progressively coarser and more scattered in such a series of cells. There is little reason to question the basophilic lineage of any of these cells. The changes in coloration are due to varying degrees of degranulation of the specific basophil granules and a simultaneous increase in the mitochondrial content of the cytoplasm. With Zenker-formalin fixation the mitochondria have been preserved, although less perfectly than with the chromeosmic fixation.

The staining of alternate $3 \mu$ sections with copper hematoxylin clearly demarcates the acidophils and shows the varying degree of mitochondrial development in the basophils, since in the latter cells only the mitochondria of the cytoplasm stain. The cytoplasm of the dark basophils appears clear with this technic. In the purplish cells the scattered mitochondria granules stand out sharply against the clear cytoplasm. They have a coarse irregular aspect and are in no way suggestive of acidophilic granules. 
The frequent presence of a large Golgi zone as well as the mitochondrial increase leads us to believe that these cells are active both in the production and in the release of a secretory substance. Their rapid increase in large numbers at the expense of the chromophobes indicates that there are many undifferentiated chromophobes which have basophilic potentiality or that chromophobes of the acidophil line are able to return to an undifferentiated state and then give rise to basophils. In the dog one is not able to differentiate the granular cells with accuracy by the shape and position of the Golgi apparatus, so that any attempt to analyze the chromophobes, as can easily be done in the rat, ${ }^{17}$ is impracticable.

Many of the mature basophils show evidence of the onset of vacuolation as described in the previous section of this paper. An irregular and massive clumping of the specific cytoplasmic granules has occurred in most of the cells. The deep blue granular masses are sometimes distributed at random throughout the cell, but more frequently are concentrated centrally near the nucleus. Surrounding them is a non-granular, amorphous cytoplasm which exhibits a variable affinity for the dyes. In dog No. 4 the hyaline substance of the majority of these cells stains a pinkish slate color even after over-extraction of the acid fuchsin and the forcing of the aniline blue. The similarity of these cells to the hyalinized basophils of the human anterior lobe in cases of pituitary basophilism is most striking (Fig. $3 \mathrm{I}$ ).

The acidophils are present in such numbers as to suggest no numerical deviation from the normal. Many of the cells are small and compact and well granulated, but some are large and have a prominent Golgi zone. In many of these the granulation is more sparse. The nuclei are on the whole normal, there being no excessive amount of lobulation or pyknosis. Scattered among the normal acidophils are cells which stand out because of their brilliant fuchsin staining. These cells range in size from cells smaller than the normal acidophils to cells considerably larger. Their shape is often irregular. Cytoplasmic granules cannot be resolved. The nucleus is pyknotic and basophilic. These cells, plentiful in the antihormone serum-injected dogs, can be found by search in the dogs injected with pituitary extract for prolonged periods. Their numerical difference in the two groups is obvious, even with 
a cursory examination of the slides. These atypical acidophils are not unlike cells to be described presently in the anterior lobe of the pituitary in sheep following prolonged injections of pituitary extract. In the sheep one can observe stages in the transformation of normal granular acidophils into these cells. In the dog one has no clue either as to their origin or significance.

The hypophyses of the antihormone serum-injected dogs show a marked hyperemia and edema. A careful microscopic study of these conditions has revealed some very interesting facts. The capillaries appear either as large sinusoids distended with blood cells, or as contracted capillaries of small diameter. These latter usually run through an edematous area which approximates the size of the most distended capillaries (Figs. 32, 33). In general, the edematous area is filled with a blue granular substance which has all the characteristics of basophilic granules. In fact, under the lower magnifications, one gains the impression that these extracellular granules are areas of basophilic cells. On numerous occasions the granules of such areas are directly continuous with the dispersing basophilic granules of bordering cells. This phenomenon can also be found at places along the distended capillaries (Fig. 30). It is common also to find blood cells within the edematous area outside the capillary wall. Since the tissue is excellently preserved, there can be but one interpretation, namely that the capillaries are in frequent communication with the edematous areas and that active degranulation of the cells is taking place into these areas as well as into the capillaries directly. The cytoplasmic granules are still recognizable in the blood plasma * (see Figs. 30 and 33).

\section{(C) Anterior Lobe of the Ewe Lamb after Prolonged Injection with Sheep Pituitary Extract}

The hypophyses to be described in this section are from 3 highly inbred ewe lambs Io months of age. The 2 injected animals were twins, and the normal control a half-sister.

\footnotetext{
* For the sake of emphasis one of us (A. E. S.) wishes to state that during the last ro years devoted largely to a cytological study of the endocrine glands, granular substances within the blood plasma have been noted on numerous occasions. On no occasion, however, have these been looked upon as cytoplasmic in origin, but rather as coagulation products of the plasma. In the present highly activated glands, however, we have not the slightest reservation concerning the identity of these granules.
} 
The anterior lobe of the pituitary in sheep is normally predominantly acidophilic. Limited areas of basophils are found peripherally and may extend here and there as solid cords of basophilic cells into the deeper portions of the gland. In addition to these cords, there are scattered isolated basophils throughout the entire glandular area. As in all other species, the basophils may be found in varying degrees of degranulation but the majority of the cells have a cytoplasm well filled with distinct basophilic granules which stain brilliantly with aniline blue after Zenker-formalin fixation. The Golgi region is not sharply demarcated in the heavily granulated cells, but in the degranulating cells it is seen as a prominent cytoplasmic structure, somewhat acidophilic in coloration due to the abundance of mitochondria in this region.

The acidophils have a distinctly granular cytoplasm and a nucleus with a network of chromatin and one or two large nucleoli.

However, various modifications of the acidophils occur, and these again closely approximate the stages described for the secretory cycle in the acidophils of the human hypophysis (Severinghaus ${ }^{21,23}$ ). In addition to nuclear and cytoplasmic granular changes, the acidophils of the sheep exhibit a great variety of shapes. Round, ovoid or polyhedral shapes are common. Frequently cells are elongated and it is not uncommon to find a whole row of elongate, almost columnar cells bordering a sinusoid. In a recent paper Warbritton and McKenzie ${ }^{34}$ describe as many as nine types of cells in the ewe, in place of the traditional three. Among their criteria of classification are the shape of cells and the degree of granulation. We have found no cells in the anterior lobe of the pituitary in sheep which could not be recognized as either acidophil, basophil or chromophobe. Variability in the size and shape of glandular cells, which constantly occurs with the elaboration and discharge of secretory products by the cell, can hardly be acceptable criteria for separating cells into distinct types, in the sense that chromophobes, acidophils and basophils are separable.

One modification of the acidophil is deserving of special mention. Occasional cells are present with a homogeneous, nongranular cytoplasm which stains brilliantly with acid fuchsin. The nuclei of these cells are highly pyknotic and basophilic. The cells 
are very irregular in shape. It is evident from cells in which granular and non-granular areas are associated in varying proportions that these hyalinized cells are modified acidophils.

The hypophyses of the twin ewes which were injected with an extract of sheep pituitary gland are clearly modified. The most striking change is an almost universal degranulation of the basophilic cells (Fig. 28). It requires considerable search to locate a normally granulated basophil. Mitochondria and the Golgi apparatus are prominent in the degranulating basophils. The acidophils seem increased in size, are compactly granulated, and stain more brilliantly than do the cells of the control. The cells with a brilliant acidophilic hyaline cytoplasm are much more numerous, as are the transitional stages in which a partial granulation still remains. Areas of small acidophils with pyknotic basophilic nuclei are common. These glands give cytological evidence in both chromophilic cells, but especially in the basophils, that the secretory activity of the anterior hypophysis is considerably increased over the normal.

\section{Discussion and Conclusions}

We are not able at this time to offer a thorough interpretation of the observations that have been described above. We may, however, emphasize what seem to us to be the more important observations. In the first place, the "Crooke changes" heretofore described only in the human pituitary gland have now been experimentally produced in dogs. Although individual cells with the Crooke change were found in the hypophyses of the dogs that had prolonged injections of anterior pituitary lobe extract, they were much more common in those dogs injected with the antihormone serum. Basophilic changes, characteristic of castration and thyroidectomy, on the contrary, were the outstanding characteristics of the former group presumably because of the longer period of injections.

The profound changes in the anterior lobe of the pituitary described in these experiments would have little interest or value unless we attempted to gain from them some insight into the physiological processes with which they are associated. In other words, the question of major importance is, "How are these cytological changes produced?" It is obvious that the proper correla- 
tion of sufficient data of this character must eventually lead to a correct understanding of the glandular functions.

A number of possibilities immediately suggest themselves. In the first place, it is conceivable that the anterior lobe is being damaged by cytotoxins which the extended injections may call forth. Or again, the changes may be produced by the direct effects of the injected pituitary extract or indirectly through the increased secretions of other endocrine glands which the injections may have activated. In this connection it is necessary to know whether the effective principles are of anterior lobe origin or whether other pituitary hormones (antidiuretic, and so on), which we know to be present in the extract, are also involved. In the third place, the anterior lobe changes may be due directly or indirectly to the antihormones which have been elaborated. Finally, one must ask if the changes indicate the elaboration of the antihormone by the hypophysis itself.

Some of these questions seem rather easily disposed of. It is not likely that the antidiuretic principle is responsible for the gross cytological changes in the anterior lobes of these dogs. The hypophysis of the ewe injected with the sheep extract known to contain the antidiuretic hormone gave evidence of secretion activation but showed none of the profound basophilic changes seen in the dogs injected with the antiserum or the pituitary gland extract.

The evidence further indicates that the observed changes are not to be attributed to the actual elaboration of the antihormones by the pituitary glands. Considerable data are now available to show that the antihormones are produced in the body tissues even in the absence of the hypophysis. Our results contain nothing to lead us to question the assumption that the antihormones are produced in such a likely site, for example, as the reticuloendothelial system.

Direct experimental evidence seems difficult to obtain either for or against the supposition that damage to the hypophysis by the action of cytotoxins may result from prolonged injection of pituitary extract. The possible rôle of the Forssman reaction in this problem remains to be investigated.

The dissimilarity of the effect upon the dog and sheep hypophysis and upon other endocrine glands after similar prolonged 
injections of pituitary extract makes it difficult to assume that the anterior lobe changes are due solely to the direct action of the injections. This fact likewise lessens the possibility that the injections activated the other endocrine glands which in turn produced the changes finally seen in the hypophyses. It is true that the initial effect upon the hypophyses in all of the animals here described has seemed to us to be a stimulation of secretory activity. We believe this to be due to an activation, by the injections, of the gonads and thyroid (adrenals?) whose hormones in turn affect the hypophysis. The anterior hypophysis of the injected ewe remains in this state of hyperactivity even after 6 months of daily injection. The antiserum-injected dogs have hypophyses which show in part signs of increased activity and in part evidences of retrogression, perhaps the result of a preceding exhaustion through abnormal activity. The pituitary-injected dogs alone show the widespread changes, especially in the basophilic cells, which combine the characteristics of the Cushing syndrome of castration and of thyroidectomy.

The early stages in the phenomena of basophilic vacuolation, which we regard as an indication of reduced rather than increased secretory activity, might be expected in the hypophyses of dogs injected with the antihormone serum. If the antihormones begin a neutralization of the hypophyseal hormones, as in the phenomena of immunization, then the thyroid, gonads and other glands would begin to suffer the effects of pituitary deprivation. The result of their progressively decreasing activity should eventually be an effect upon the anterior lobe simulating a total ablation of this organ.

Those anterior lobe features resulting from antihormone-serum injections, which we have interpreted above as evidence of increased hypophyseal secretion production and release, are more difficult to understand. We know that the earliest effects upon the hypophysis of total ablation of the thyroid or gonads are in part activating rather than depressing. This is shown by the great numerical increase of basophils at the expense of chromophobes. Cytologically, however, such cells proceed rapidly to vacuolation and do not give evidence of increased secretory release as do those large areas of basophils in the hypophyses of antihormone-seruminjected dogs. Moreover, we have no right to assume that by de- 
pressing a gonad or thyroid we immediately completely inactivate it, and thus produce in the experimental animal a situation comparable to the earliest period of total glandular ablation.

It should be pointed out that many investigators believe in the activation of secretory processes in the pituitary gland by a suppression of the gonads. This view is based on a considerable body. of evidence, especially that derived from certain parabiotic experiments and from a comparative analysis of the hormone content, supposedly of anterior lobe origin, in the urine of pre- and postmenopausal women. The evidence for a diametrically opposite view, which cytological studies in a wide variety of experimental procedures have confirmed without exception, has been presented elsewhere (Severinghaus ${ }^{22}$ ). Although progress is evident of a harmonization of these conflicting views, the matter is far from being settled. We need not be unduly exercised over these discrepancies, but that we recognize them is of first importance. Discrepancies are the rich deposits of discovery. They indicate the points at which our efforts should be redoubled.

One great difficulty in attempting to interpret the results of the present experiments lies in the fact that massive dosages have been employed. Errors may readily be committed by attempting to impute the normal physiological glandular interplay to experiments in which the whole organism may have been thrown into a state of physiological disorder by an intolerable, massive administration of a certain potent hormone. In this condition it is conceivable that the activity of a gland may be altered quantitatively and qualitatively, and that further complications arise if, at the same time, the end organs lose their capacity to respond normally.

Fully realizing the difficulties involved, we venture to go beyond a mere recital of our cytological findings and state that to us the most reasonable interpretation of the cytological changes in the anterior hypophysis, due to prolonged administration of pituitary extract, is obtained by assuming that the following reactions occur in sequence in the experimental animal:

I. Injection of pituitary extract activates the endocrine glands related to the anterior lobe, namely, gonads, thyroid, and probably adrenals.

2. The increased secretion of these activated glands in turn stimulates the anterior lobe which augments with its own secretion 
the injected extract. This was seen in the case of the treated ewes.

3. The excess of extract of the anterior lobe of the pituitary from a foreign species results in the development of a humoral resistance (immunity) which manifests itself by the production of antihormones.

4. The antihormones at first neutralize the injected pituitary extract, and later the secretion of the hypophysis of the injected animal itself. Thereafter the end organs (gonads, thyroids, adrenals) react by atrophy as in states of pituitary insufficiency, even though the hypophysis continues its activity.

5. The atrophy of these related glands in turn brings about in the anterior lobe certain changes which are characteristic of gonadectomy and thyroidectomy (adrenalectomy?). A combination of these effects well describes the condition actually observed in the anterior lobe of the pituitary.

The Crooke changes, usually associated with hyperactivity of the adrenal cortex, but also with hypothyroid and hypogonad states are most closely simulated in the antiserum-injected dogs in which the adrenals are not greatly altered.

Although the animals exhibit some of the characteristics of hypophysectomy, it is evident that injections have accomplished a relatively complete thyroidectomy without surgical interference. The lowered basal metabolic rate, hypercholesterolemia, and the histological appearance of the pituitary are proof of this fact. The atrophic thyroid gland and the above facts contribute proof that in this case function and histological appearance in the thyroid were also correlated.

One cannot say from the experiment whether the hypophysis which results from prolonged pituitary extract injection and which shows the changes normally following thyroidectomy and gonadectomy has been inactivated, or whether a normal or even increased output of secretion is taking place. Regardless of the rate of secretion release, the hormones are constantly being neutralized by the circulating antihormones. On cytological grounds it can be said that the hypophysis continues some of its secretory activity. Certain of its products may be inactivated by the antihormones, so plentiful in the blood, while others may be unaffected, thus resulting in a state not entirely comparable to hypophysectomy. 


\section{REFERENCES}

I. Anderson, Evelyn M., and Collip, J. B. Studies on the physiology of the thyreotropic hormone of the anterior pituitary. J. Physiol., 1934, 82, II-25.

2. Calder, Royall M., and Porro, F. W. Adenoma of adrenal cortex simulating pituitary basophilism. Bull. Johns Hopkins Hosp., 1935, 57, 99-i ro.

3. Collip, J. B. Results of further experiments with the anti-maturity hormone. Canad. M. A. J., 1937, 36, 199-200.

4. Collip, J. B., and Anderson, Evelyn M. The production of serum inhibitory to the thyrotropic hormone. Lancet, 1934, I, 76-78.

5. Crooke, A. C. A change in the basophil cells of the pituitary gland common to conditions which exhibit the syndrome attributed to basophil adenoma. J. Path. \& Bact., 1935, 41, 339-349.

6. Du Shane, G. P., Levine, W. T., Pfeiffer, C. A., and Witschi, E. Experimental "constant oestrus" and the notion of antigonadotropic hormones. Proc. Soc. Exper. Biol. \& Med., 1935, 33, 339-345.

7. Gordon, Albert S., Kleinberg, William, and Charipper, Harry A. Reticuloendothelial system and the concept of the "anti-hormone." Science, 1937, 86, 62-63.

8. Kepler, E. J., Kennedy, R. L. J., Davis, A. C., Walters, Waltman, and Wilder, R. M. Suprarenocortical syndrome and pituitary basophilism: presentation of three new cases. Proc. Staf Meet. Mayo Clin., 1934, 9, 169-181.

9. Leyton, Otto, Turnbull, Hubert M., and Bratton, Allen B. Primary cancer of the thymus with pluriglandular disturbance. J. Path. \& Bact., I931, 34, 635-660.

Io. Nelson, Warren O., and Hickman, Jane. Effect of oestrone on hypophyses and reproductive organs of thyroidectomized rats. Proc. Soc. Exper. Biol. \& Med., 1937, 36, 828-830.

II. Parkes, A. S., and Rowlands, I. W. Inhibition of ovulation in the rabbit by anti-gonadotropic serum. J. Physiol., 1936, 88, 305-31 I.

I2. Rasmussen, A. T. The relation of the basophilic cells of the human hypophysis to blood pressure. Endocrinology, 1936, 20, 673-678.

13. Rowlands, I. W. The effect of anti-gonadotropic serum on the reproductive organs of the normal animal. Proc. Roy. Soc., London, Ser. B., 1937, $121,597-632$.

I4. Rowlands, I. W. Pro-gonadotropic sera. Proc. Roy. Soc., London, Ser. B., 1938, 124, 492-503.

15. Rowlands, I. W. Specificity of antisera to gonadotropic extracts. Proc. Physiol. Soc., 1937, 90, 19-20.

16. Rowlands, I. W., and Parkes, A. S. A study of anti-thyrotropic activity. Proc. Roy. Soc., London, Ser. B., 1936, 120, I14-1 25. 
17. Severinghaus, Aura Edward. A cytological study of the anterior pituitary of the rat with special reference to the Golgi apparatus and to cell relationship. Anat. Rec., 1933, 57, 149-1 75 .

I8. Severinghaus, A. E., Smelser, George K., and Clark, Helen M. Anterior pituitary changes in adult male rats following thyroxin injections or thyroid feeding. Proc. Soc. Exper. Biol. \& Med., I934, 31, I I 25-I I 27.

I9. Severinghaus, A. E., Smelser, George K., and Clark, Helen M. Anterior pituitary changes in the adult male rat following thyroidectomy. Proc. Soc. Exper. Biol. \& Med., I934, 31, I I 27-I I 29.

20. Severinghaus, Aura E. Cytological studies on the rat pituitary after injections of pregnancy urine extract and pregnancy blood serum. Anat. Rec., I934, 60, 43-67.

21. Severinghaus, Aura E. A suggestive correlation of cytological changes with secretory activity in the cells of the normal human anterior hypophysis. Anat. Rec., I935, 61, Suppl., 6r.

22. Severinghaus, Aura E. Cellular changes in the anterior hypophysis with special reference to its secretory activities. Physiol. Rev., 1937, 17, 556-588.

23. Severinghaus, Aura E. The cytology of the pituitary gland. The Pituitary Gland. Association for Research in Nervous and Mental Diseases, Williams \& Wilkins, Baltimore, 1938, 17, 69-1 17 .

24. Smith, Philip E. The induction of precocious sexual maturity by pituitary homeotransplants. Am. J. Physiol., 1927, 80, $114-125$.

25. Smith, Philip E. Hastening development of female genital system by daily homoplastic pituitary transplants. Proc. Soc. Exper. Biol. \& Med., 1926, 24, I3I-132.

26. Thompson, $\mathrm{K} . \mathrm{W}$. Inability of sheep to develop antihormone to the gonadotropic hormone from sheep-pituitary glands. Proc. Soc. Exper. Biol. \& Med., 1937, 35, 634-637.

27. Thompson, K. W. Non-specificity of thyrotropic antihormone. Proc. Soc. Exper. Biol. \& Med., I937, 35, 637-640.

28. Thompson, $K$. W. The augmentary factor in animal sera after injections of pituitary extract. Proc. Soc. Exper. Biol. \& Med., 1937, 35, 640644 .

29. Thompson, K. W. The termination of pregnancy of dogs by gonadotropic antihormone. Endocrinology, 1939, 24, 613-616.

30. Thompson, K. W., and Cushing, H. Experimental pituitary basophilism. Proc. Roy. Soc., London, Ser. B., 1934, II5, 88-100.

3r. Thompson, K. W., and Cushing, H. Inhibition of action of pituitary hormones by animal sera. Proc. Roy. Soc., London, Ser. B., 1937, 121, 501-517.

32. Twombly, Gray $H$. Studies of the nature of antigonadotropic substances. Endocrinology, 1936, 20, 311-317. 
33. Van Dyke, H. B., and Wallen-Lawrence, Zonja. Further observations on the gonad-stimulating principle of the anterior lobe of the pituitary body. J. Pharmacol. \& Exper. Therap., 1933, 47, 163-181.

34. Warbritton, V., and McKenzie, F. F. The pituitary glands of ewes in various phases of reproduction. Miss. Agric. Exper. Sta. Res. Bull., 1937, No. 27.

35. Werner, Sidney C. Prolonged injection of a thyrotropic extract without development of refractoriness. Proc. Soc. Exper. Biol. \& Med., 1936, 34, 390-392.

36. Werner, Sidney C. Antibody nature of refractoriness to injections of hypophyseal extracts containing thyrotropic hormone. Proc. Soc. Exper. Biol. \& Med., 1936, 34, 392-394.

37. Werner, Sidney $C$. The thyrotropic hormone and the antihormone problem. Endocrinology, 1938, 22, 291-301.

\section{DESCRIPTION OF PLATES}

\section{Plate 6i}

None of these photographs is retouched. They were taken at a magnification of about $950 \times$, unless otherwise designated.

FIGS. I-4 show the clumping of basophilic granules into irregular masses. The dark masses are large colloid vacuoles. The clear vacuoles are also seen in various stages in Figs. 2 and 4.

Figs. 5-9 inclusive show various stages of the transitional formation of dark granular masses into colloid vacuoles. Note their general distribution throughout the cytoplasm. The cell borders frequently become indistinct. 


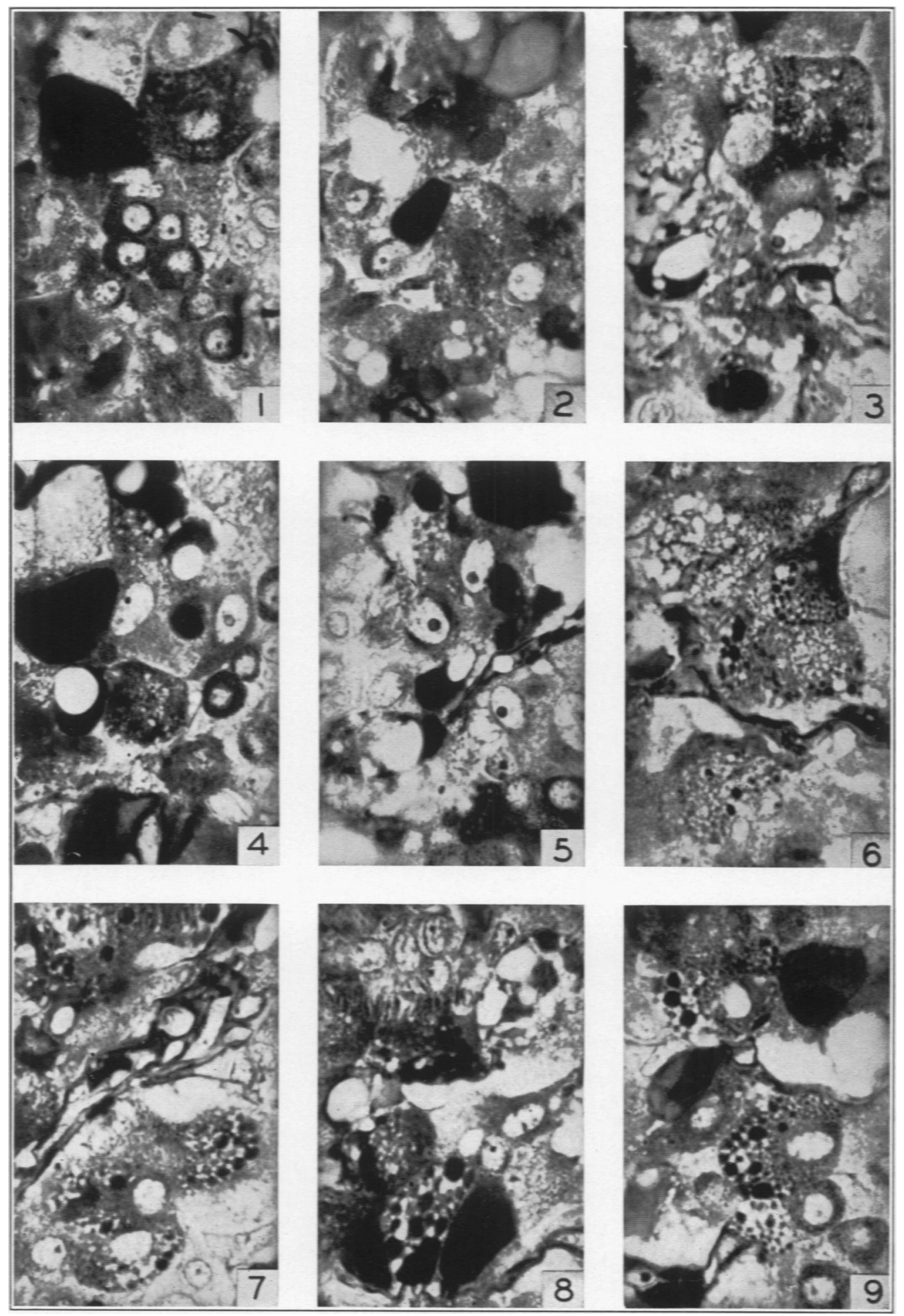




\section{Plate 68}

Figs. IO-I 2. These photographs show the presence of larger dark basophilic vacuoles and their formation from smaller ones. See especially cell in Fig. I 2. Cells in the lower left of Fig. I0. and upper and center right of Fig. I I show vacuoles of the paler basophilic substance.

FIGs. I $3^{-16}$ inclusive show the association of all 3 types of vacuoles within a single cell. In Fig. I 5 one large disintegrating basophil (chromophobe indenting on right) occupies almost the entire area below the capillary and to the right of the connective tissue fibers.

Fig. $1 ;$. A typical castration type of vacuolation is seen in the cell at the upper center.

FIG. I 8. Large basophils whose borders are indistinct border on the sinusoids. Such basophilic masses of cells are common. 


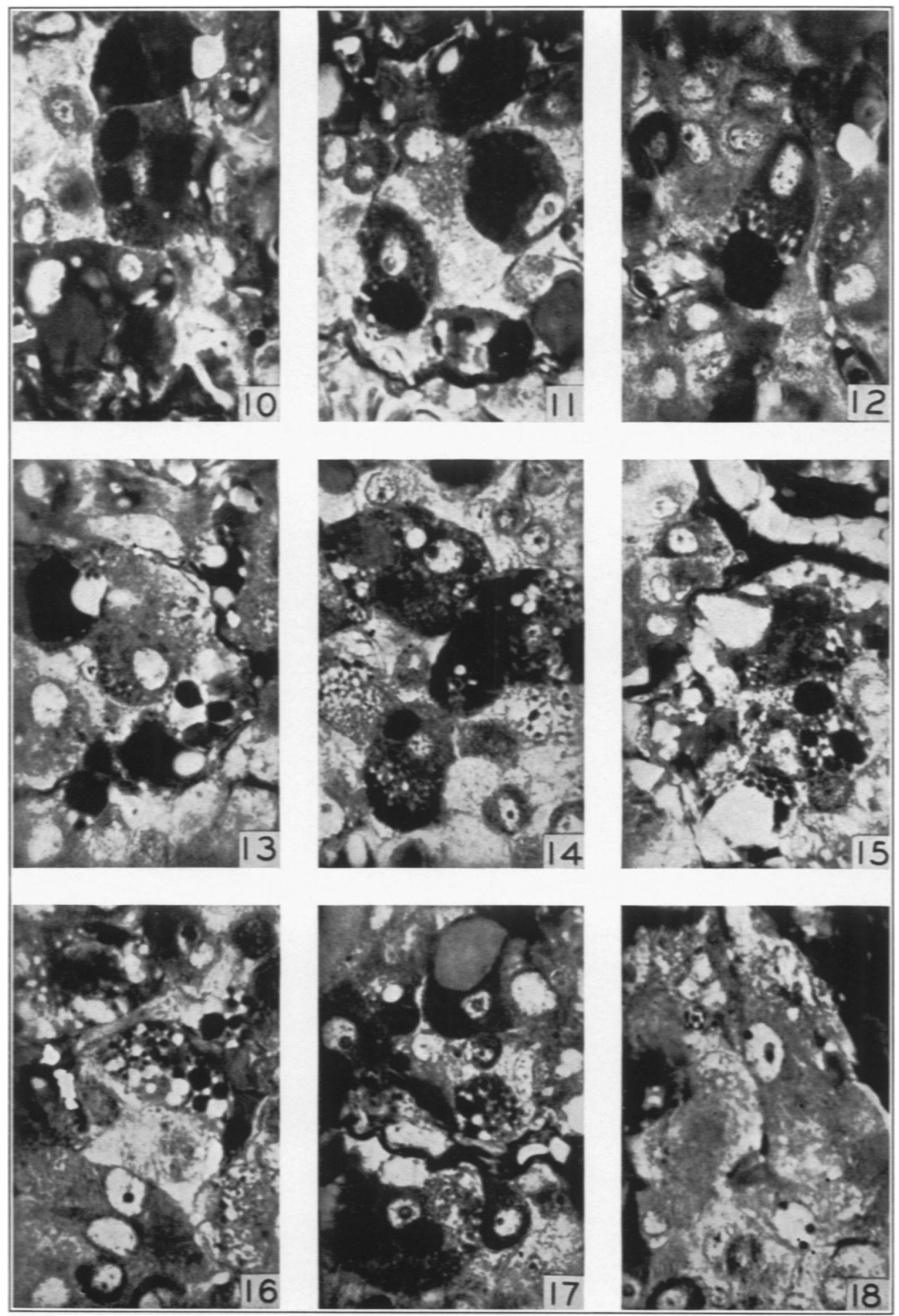




\section{Plate 69}

Figs. I9-2t show many stages in the progressive development of the clear vacuoles described in the text. With these are associated vacuoles of the other 2 types. These cells are typical of thyroidectomy changes in the basophils of the dog.

Fig. 25 shows a typical group of smaller basophils with fine cytoplasmic granulation and abundant mitochondria. These appear cytologically to be very active cells.

FIG. 26 shows a characteristic region of normal appearing acidophils.

FIG. 27 shows a characteristic region of pyknotic nucleated acidophils. an indication of cyclical secretory activity in the acidophils. See text. 

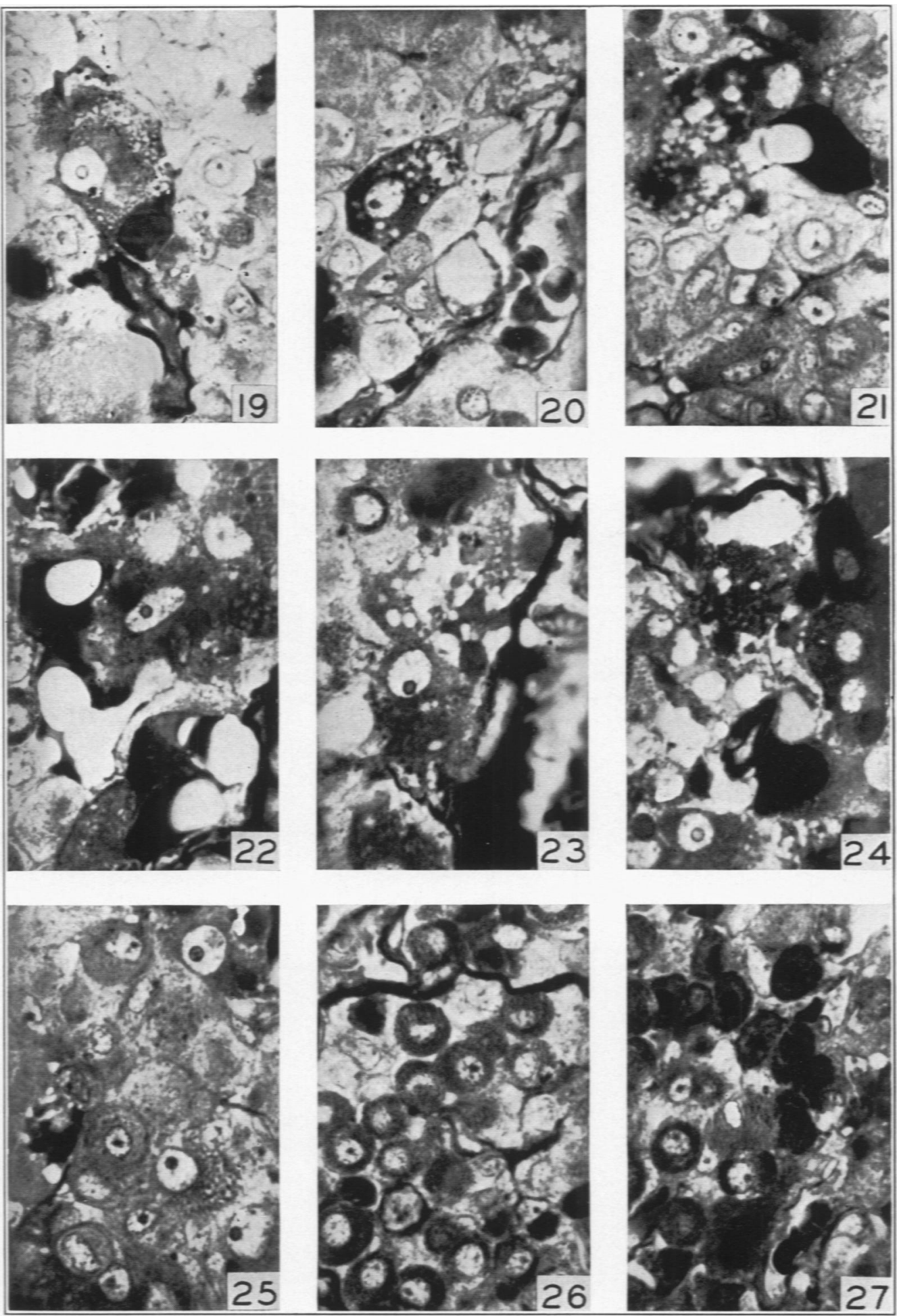


\section{Plate ;0}

FIG. 28 shows a typical area from the anterior hypophysis of a ro months old lamb injected daily for 6 months with sheep pituitary extract. The dark granulated cells are acidophils. Homogeneous black areas in the cells are hyalinized portions of the cells. The light areas are largely degranulated basophils with a sparse grayish cytoplasmic granulation. About $\times 550$.

Fig. 29 shows a control lamb hypophysis. Note the distinct basophilic (deep blue I granulation of the basophils. Only color photography could indicate the marked contrast of these two glands. About $\times 550$.

FIg. 30 shows actual degranulation of the bordering basophils into a distended sinusoid. Note the granular substance continuous across the sinusoid wall just to the right of the large central basophil. About $\times 2000$.

Fig. 3I. The large basophil in the center has cytoplasmic granulation adjacent to and below the nucleus. but the periphery of the cell has been completely hyalinized. The striking similarity to Crooke changes is obvious. $\times 2000$.

Fig. 32. Typical area of a pituitary from an antihormone-injected animal. Note the extreme hyperemia and edema. A distended sinusoid is seen at the upper right. while at the lower right and left are typical contracted capillaries within edematous areas. Note the extravasation of red cells above the capillary in the edematous area and at the left center of the figure.

Fig. 33. High power field of square in Fig. 32. In the upper left the capillary: with its distinct endothelial nuclei. lies in an edematous space which is filled with red blood cells. Numerous examples such as this give evidence of widespread communication of the capillaries with the spaces. Note that the distended capillaries approximate in a cross section area the edematous spaces. 


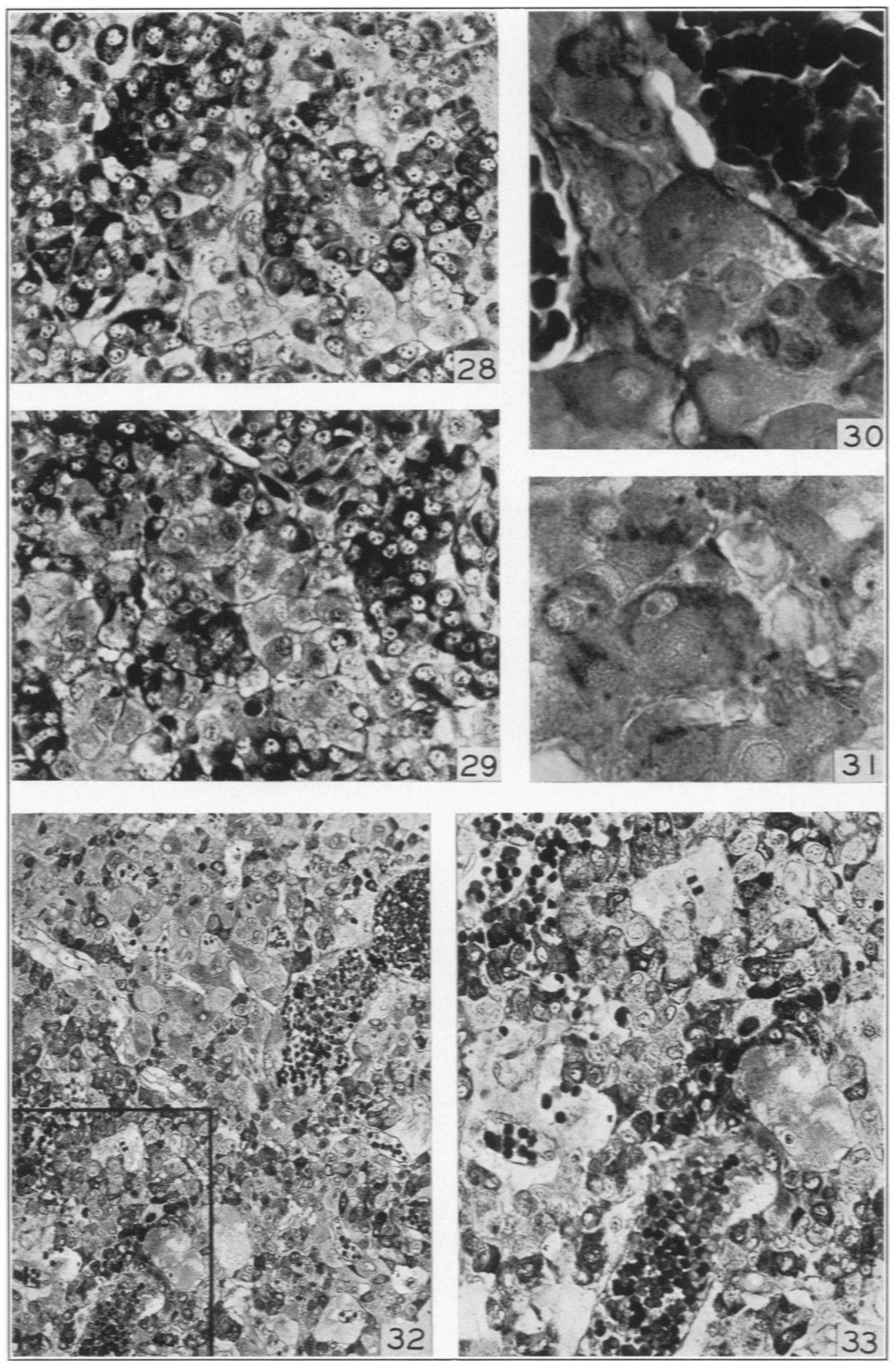

